\title{
Effect of Phosphine Gas Conditions on Structural, Optical and Electrical Properties of Nc-Si:H Films Deposited by Cat-CVD Method
}

Bharat Gabhale, ${ }^{1}$ Haribhau Borate, ${ }^{1}$ Subhash Pandharkar, ${ }^{1}$ Ajinkya Bhorde, ${ }^{1}$ Rahul Aher, ${ }^{1}$ Shruthi Nair, ${ }^{1}$ Priti Vairale, 1 Ashvini Punde, ${ }^{1}$ Ashish Waghmare, ${ }^{1}$ Vijaya Jadkar, ${ }^{1}$ Vidya Doiphode, ${ }^{1}$ Yogesh Hase, ${ }^{1}$ Nilesh Patil,,${ }^{1}$ Sachin Rondiya,${ }^{1}$ Pratibha Shinde, ${ }^{1}$ Mohit Prasad ${ }^{2}$ and Sandesh Jadkar ${ }^{2 *}$

\begin{abstract}
Herein n-type hydrogenated nano-crystalline silicon (nc-Si:H) thin films were synthesized using silane $\left(\mathrm{SiH}_{4}\right)$ and phosphine $\left(\mathrm{PH}_{3}\right)$ acted as a dopant gas by catalytic chemical vapor deposition technique (Cat-CVD). The substrate temperature was maintained at $200{ }^{\circ} \mathrm{C}$. The effect of $\mathrm{PH}_{3}$ flow rate on opto-electronic and structural properties of nc-Si: $\mathrm{H}$ was studied using UV-visible spectroscopy, dark conductivity, low angle X-ray powder diffraction (XRD), Raman spectroscopy, etc. From low angle $\mathrm{XRD}$ and Raman analysis, it was observed that the incorporation of phosphorus atoms in nc-Si:H caused the transformation nc-Si:H to a-Si:H. At optimized $\mathrm{PH}_{3}$ flow rate $(0.3 \mathrm{sccm})$, n-type nc-Si:H films from a high deposition rate ( $\left.29.6 \AA ̊ \Omega / s\right)$ had an optimum band gap ( $1.89 \mathrm{eV})$, high dark conductivity $(\sim 1.52 \mathrm{~S} / \mathrm{cm})$ and low charge carrier activation energy $(0.19 \mathrm{eV})$ at low hydrogen content ( 1.83 at. \%). The deposited films can be useful as n-layer Si:H based c-Si heterojunction solar cells.
\end{abstract}

Keywords: Cat-CVD; nc-Si:H films; Amorphization; Raman spectroscopy.

Received: 30 October 2018; Accepted date: 21 November 2020.

Article type: Research article.

\section{Introduction}

As of today, crystalline silicon (c-Si) has the lion's share in electronic devices and solar photovoltaic (SPV) market. However, the opto-electronic devices fabricated using c-Si have several limitations such as a weak response to the absorption in the visible region of solar spectrum due to its indirect band gap and high wafer processing cost. To overcome these limitations, hydrogenated amorphous silicon $(\mathrm{a}-\mathrm{Si}: \mathrm{H})$ has been investigated for the fabrication of photodiodes, transistors (TFTs), gas sensors, liquid crystal displays and solar cells. ${ }^{[1]}$ But it was observed that the devices made from a-Si:H have a poor stability due to the presence of hydrogen related defects. ${ }^{[1]}$ As compared to a-Si:H, nc-Si:H has high stability, carrier mobility and good absorption in the lower energy region of solar spectrum. ${ }^{[2]}$ Due to enhanced

\footnotetext{
${ }^{1}$ School of Energy Studies, Savitribai Phule Pune University, Pune 411007 (India)

${ }^{2}$ Department of Physics, Savitribai Phule Pune University, Pune 411 007 (India)

*Email:sandesh@physics.unipune.ac.in (S. Jadkar)
}

properties, nc-Si:H containing embedded Si nano-crystals in amorphous matrix, has important new applications in the field of photovoltaic solar cells and nano-electronic devices. ${ }^{[3-7]}$ The nc-Si:H has high dark and photo conductivity, high mobility and good doping efficiency. ${ }^{[8-10]}$ Since nc-Si:H has an ordered structure, thus it is more stable against light induced degradation. ${ }^{[1]}$ Thus, nc-Si:H is more suitable as compared to a-Si:H thin film technology. For example, Shah et at. ${ }^{[12]}$ have synthesized nc-Si:H and embedded it as absorber layer in the solar cells showing an efficiency of $10.1 \%$. Using nc-Si:H in tandem/micromorph solar cells, Yamamoto et at. ${ }^{[30]}$ reported an initial efficiency of $\sim 14.7 \%$. Also, p-type nc-Si:H has been used as window layer in a-Si:H solar cells. ${ }^{[14,15]}$

Different techniques have been used for the synthesis of nc-Si:H films, such as plasma enhanced chemical vapor deposition [PE-CVD], microwave PE CVD, ${ }^{[17]}$ electron beam evaporation, ${ }^{[18]}$ electron cyclotron resonance $\mathrm{PE} \mathrm{CVD},{ }^{[19]} \mathrm{RF}$ magnetron sputtering, ${ }^{[20]}$ hot wire $\mathrm{CVD}_{,}^{[21]} \mathrm{Si}$ ion implantation, ${ }^{[22]}$ cathodic vacuum arc ${ }^{[23]}$ etc. Out of these techniques, PE-CVD has been extensively used for industrial applications. For the synthesis of nc-Si:H films using PECVD, it is necessary to maintain high RF power and hydrogen dilution of silane. The silane dilution by $\mathrm{H}_{2}$ causes the 
formation of unwanted metastable states ${ }^{[24]}$ as well as reduces the rate of deposition. ${ }^{[25]}$ High RF power affects transparent conducting coatings (TCO), ${ }^{[26]}$ which are the base of the solar cells. Therefore, due to such difficulties associated with PECVD, there was a need for another efficient technique for the synthesis of nc-Si:H films. In recent years, the catalytic chemical vapor deposition technique (Cat-CVD) is widely used for the preparation of highly stable nc-Si:H films, which have a high growth rate. ${ }^{[27,28]}$ Therefore, it is obligatory to prepare intrinsic and doped nc-Si:H using Cat-CVD technique, so that it can be used as a good alternative for PE-CVD.

In the present work, the opto-electronic and structural properties of phosphorus doped nc-Si:H films synthesized by Cat-CVD technique were studied. The effect of $\mathrm{PH}_{3}$ flow rate on dark conductivity, deposition rate, activation energy, hydrogen content, volume fraction of crystallites, crystallite size and optical band gap were studied. The structural properties of doped nc-Si:H critically were found to depend on dopant $\mathrm{PH}_{3}$ gas flow rate and the incorporation of phosphorus atoms in nc-Si:H caused the transformation to a-Si:H.

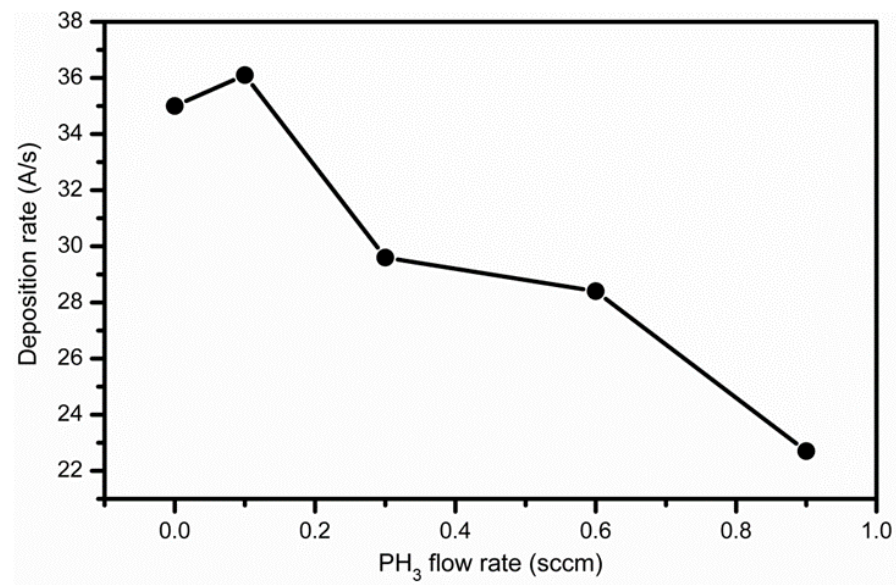

Fig. 1 Variation of deposition rate as a function of $\mathrm{PH}_{3}$ flow rate for $\mathrm{Si}: \mathrm{H}$ films deposited by Cat-CVD technique.

\section{Experimental Section}

\subsection{Preparation of nc-Si:H films}

Undoped and phosphorus doped nc-Si:H films were deposited at the same time on corning (\# 7059) glass and c-Si wafer by Cat-CVD technique. The Cat-CVD technique had a process chamber along with a load lock chamber. The process chamber consisted of two pumps: one turbo molecular pump along with rotary vane pump. To load and un-load the substrates, the load lock chamber was used, which prevented direct exposure of process chamber to the atmospheric air. The pneumatically controlled transport arm transferred the substrate from loadlock to the process chamber. The deposition pressure was maintained by adjusting the throttle valve manually. Ten straight parallel tungsten filaments separated by $1 \mathrm{~cm}$ distance having diameter $0.05 \mathrm{~cm}$ and length $100 \mathrm{~mm}$ were used. The filaments were heated by passing high current $(\sim 25 \mathrm{~A})$ through each filament. The optical pyrometer (IRCON Infrared thermometer, USA) had been used to measure the filament temperature. The flow rates of the gases coming from the cylinders were controlled by mass flow controllers. Before entering the process chamber, all gases were allowed to mix in the gas mixer. After that, the mixture of the gases was passed through gas shower into the process chamber just below the plane of the parallel tungsten filaments. The gas shower was such designed so that the density of gas molecules on the tungsten filaments should remain uniform. In between substrates and filaments, there was a shutter to avoid predeposition. The substrates were fixed on the substrate holder and the desired temperature was achieved using a built-in heater. The substrate temperature was measured by a thermocouple sensor. Undoped and phosphorus doped nc-Si:H films were deposited without hydrogen dilution using a combination of pure silane $\mathrm{SiH}_{4}$, Matheson Semiconductor Gas (MSG)) as a source of silicon and phosphine $\left(\mathrm{PH}_{3}\right.$, Matheson Semiconductor Gas (MSG)]) dopant gas, which is a source of phosphorus. The deposition parameters for the preparation of films are listed in Table 1.

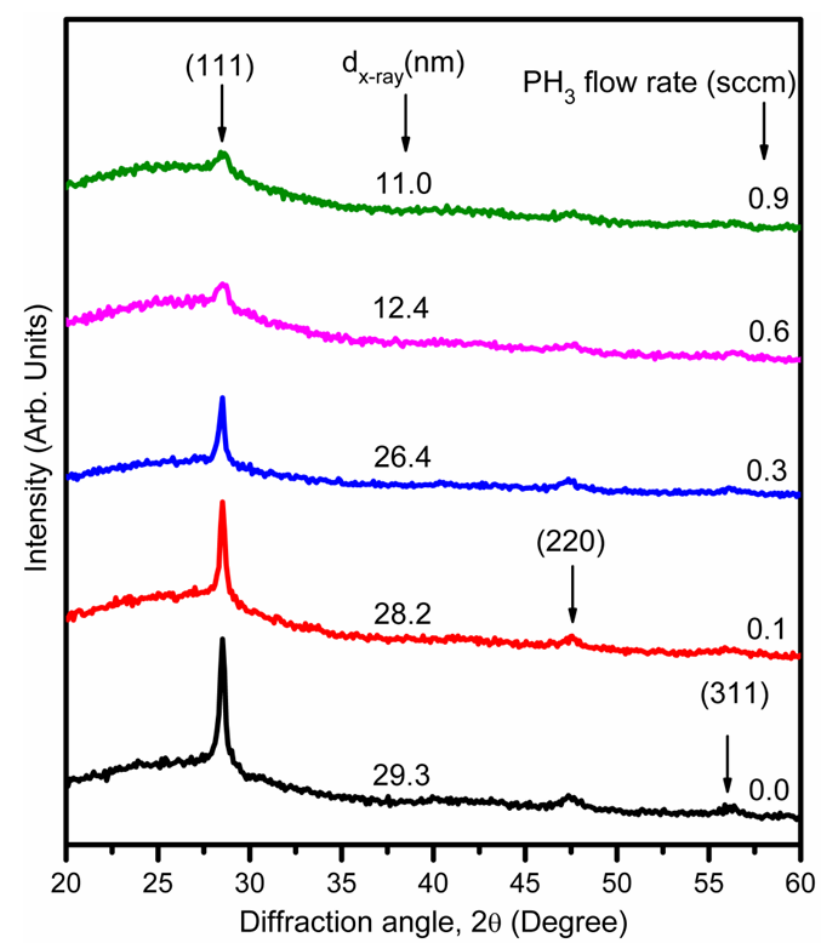

Fig. 2 Low angle diffraction pattern of phosphorus doped nc-Si:H films deposited at different $\mathrm{PH}_{3}$ flow rate by Cat-CVD technique.

Table 1. Deposition parameters used for the synthesis of phosphorus doped nc-Si:H films by Cat-CVD technique.

\begin{tabular}{ll}
\hline Process parameters & Value \\
\hline Substrate temperature $\left(\mathrm{T}_{\mathrm{Sub}}\right)$ & $200{ }^{\circ} \mathrm{C}$ \\
Filament temperature $\left(\mathrm{T}_{\mathrm{Fil}}\right)$ & $1900{ }^{\circ} \mathrm{C}$ \\
Filament to substrate distance $\left(\mathrm{d}_{\mathrm{f}-\mathrm{s}}\right)$ & $5.0 \mathrm{~cm}$ \\
Gas flow rates: & \\
1) Silane $\left(\mathrm{F}_{\mathrm{SiH} 4}\right)$ & $2 \mathrm{sccm}$ \\
2) Phosphine $\left(\mathrm{F}_{\mathrm{PH} 3}\right)$ & $0.0-0.9 \mathrm{sccm}$ \\
Deposition pressure & $300 \mathrm{mTorr}$ \\
Deposition Time & $10 \mathrm{~min}$ \\
\hline
\end{tabular}


The glass substrates were cleaned with piranha solution $\left(80 \% \mathrm{H}_{2} \mathrm{SO}_{4}+20 \% \mathrm{H}_{2} \mathrm{O}_{2}\right)$ and the c-Si wafers were immersed in $\mathrm{HF}$ for 2-3 min for etching the oxide layer formed on the surface. After fixing the substrates to the substrate holder, the process chamber was evacuated to pressure less than 10-6 Torr. During each deposition, initially the tungsten filaments were heated to about $2000{ }^{\circ} \mathrm{C}$ in the presence of atomic hydrogen to remove the oxide layer formed on the filament surface. After each deposition, the films were allowed to cool in vacuum.

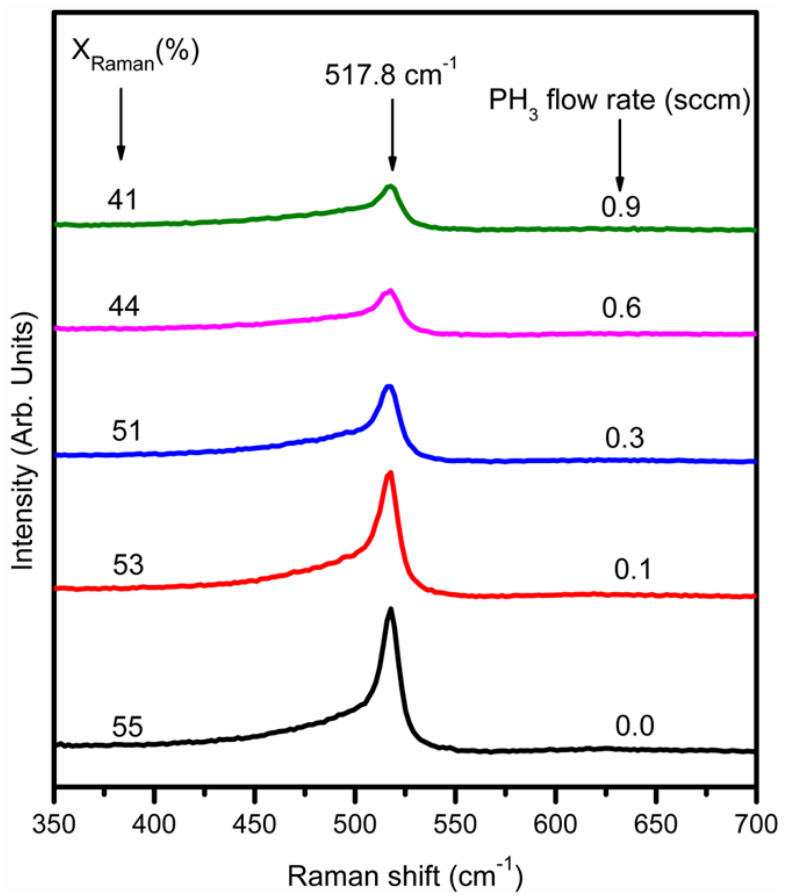

Fig. 3 Room temperature Raman spectra of phosphorus doped nc$\mathrm{Si}: \mathrm{H}$ films deposited at different $\mathrm{PH}_{3}$ flow rates by Cat-CVD technique.

\subsection{Characterization of nc-Si:H films}

Dark conductivity $\left(\sigma_{\text {Dark }}\right)$ and charge carrier activation energy $\left(E_{a c t}\right)$ was measured using Keithley source meter (2401). The dimensions of the samples used for measurements were $3 \mathrm{~cm}$ x $1 \mathrm{~cm}$. For the measurement of $\sigma_{\text {Dark }}$ and $E_{\text {act }}$, two $\mathrm{Al}$ electrodes separated by $0.05 \mathrm{~cm}$ distance were deposited by thermal evaporation technique. XRD patterns were taken using x-ray diffractometer (Bruker D8 Advance, Germany) with $\mathrm{Cu} \mathrm{K} \mathrm{K}_{\alpha}$ line $(\lambda=1.54056 \AA)$ at a grazing angle of $1^{\circ}$. Raman spectra were recorded using Jobin Yvon Horibra LABRAM-HR in the wavelength range $350-700 \mathrm{~nm}$ with a resolution of $1 \mathrm{~cm}^{-1}$. The excitation wavelength used was $632.8 \mathrm{~nm}$ having a penetration depth of $\sim 1 \mu \mathrm{m}$. The laser power was maintained at $5 \mathrm{~mW}$ to avoid any damage in the films. To calculate the total bonded hydrogen content in the films, FTIR spectrophotometer (JASCO, 6100-TYPE A) in transmission mode was used. The optical band gap of films was obtained by using UV-Visible spectra in transmission and reflection mode, which was recorded using a dual beam Hitachi UV-Visible spectrophotometer. The thickness of each film was obtained using a surface profiler (KLA Tencor, P$16+$ ), which can also be substantiated from UV-visible spectroscopy analysis by following the procedure given by Swanepoel. ${ }^{[29]}$

\section{Results and Discussion}

\subsection{Variation of deposition rate}

The change in deposition rate as a function of $\mathrm{PH}_{3}$ flow rate for nc-Si:H films is shown in Fig. 1. The deposition rate was calculated from the film thickness and deposition time. The film thickness was measured using a taly-step surface profilometer. For the undoped $\left(\mathrm{F}_{\mathrm{PH} 3}=0.0 \mathrm{sccm}\right) \mathrm{nc}-\mathrm{Si}: \mathrm{H}$ film, the deposition rate was $\sim 35 \AA / \mathrm{sec}$. The deposition rate was $\sim$ $36.1 \AA / \mathrm{s}$ when the $\mathrm{PH}_{3}$ flow rate was maintained at $0.1 \mathrm{sccm}$. As the $\mathrm{PH}_{3}$ flow rate was further increased, the deposition rate went on decreasing continuously and finally it came to $\sim 22.7$ $\AA / \mathrm{sec}$ for $\mathrm{PH}_{3}$ flow rate of $0.9 \mathrm{sccm}$. The increase in density of film forming radicals may be the reason for initial increase in deposition rate. In present study, $1 \%$ of $\mathrm{PH}_{3}$ in hydrogen had been used as the dopant gas. An increase in $\mathrm{PH}_{3}$ flow rate elevateed the density of atomic $\mathrm{H}$. Atomic $\mathrm{H}$ is an efficient etchant in Cat-CVD process. Thus, as the $\mathrm{PH}_{3}$ gas flow rate was increased, a decrease in deposition rate occurred due to the etching effect of atomic $\mathrm{H}$. The deposition rate obtained in current study was much higher than the previously reported deposition rates for phosphorus doped nc-Si:H films. ${ }^{[30-32]}$ For the industrial applications, it is necessary to have a higher deposition rate, as it reduces the processing time and ultimately production cost.

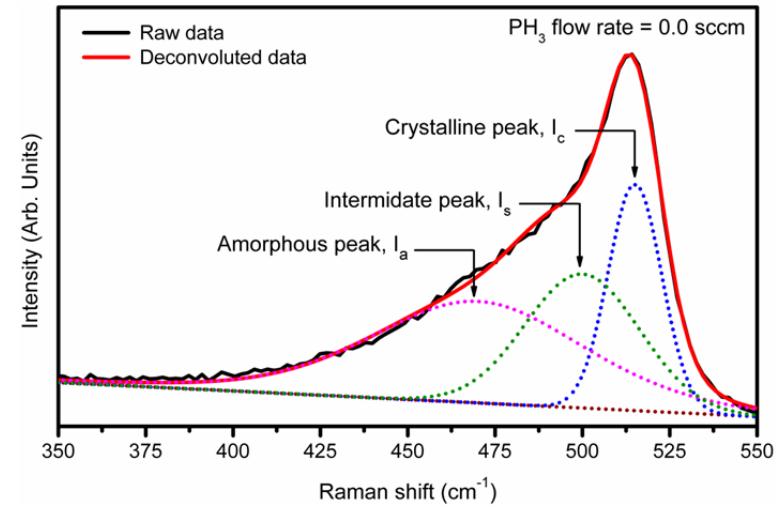

Fig. 4 Typical de-convoluted Raman spectrum $\left(\mathrm{PH}_{3}\right.$ flow rates= $0 \mathrm{sccm}$ ) using Levenberg-Marquardt method for the estimation of volume fraction of crystallites and crystallite size of phosphorus doped nc-Si:H films.

\subsection{Low angle $X$-ray diffraction analysis}

The XRD pattern of nc-Si:H thin films deposited on corning (\# 7059) glass substrates at different $\mathrm{PH}_{3}$ flow rates is shown in Fig. 2. As shown in Fig. 2, the $\mathrm{Si}: \mathrm{H}$ film deposited at $\mathrm{PH}_{3}$ flow rate $=0.0 \mathrm{sccm}$ (pure) is nano-crystalline with three different peaks at $2 \theta \sim 28.5^{\circ}, 47.3^{\circ}$ and $56.1^{\circ}$, having the crystal orientations along (111), (220) and (311), respectively. The highest intensity peak is observed at $2 \theta \sim 28.5^{\circ}$, indicating that the growth of the crystallites is dominant along (111) 
direction. However, as the $\mathrm{PH}_{3}$ flow rate is increased, the intensities of all the crystallographic planes are decreased. This decrease in diffraction peak intensity with increasing the $\mathrm{PH}_{3}$ flow rate is due to the decrease in the crystalline volume fraction in the Si:H films. Thus, the addition of phosphorus in the nc-Si:H network promotes amorphization. The transition from nano-crystalline to amorphous upon the addition of phosphorus is further confirmed by Raman spectroscopy analysis (discussed later). This transition may be due to the local disturbance caused by the dopant phosphorus atoms in the nc-Si:H network.

The average crystallite size (dx-ray) corresponding to the (111) crystallographic plane for all phosphorus doped nc-Si:H films was calculated using Scherrer formula, Equation (1):[33]

$$
d_{x-\text { ray }}=\frac{0.9 \lambda}{\beta \cos \theta_{B}}
$$

where $\lambda$ is the wavelength of the incident $x$-ray $(1.54 \AA), \beta$ is the full width at half maximum (FWHM) of the (111) peak, and $\theta_{\mathrm{B}}$ is the angle of diffraction. It is observed that, as the $\mathrm{PH}_{3}$ gas flow rate increases from 0.0 to $0.9 \mathrm{sccm}$, the crystallite size decreases from 29.3 to $11.0 \mathrm{~nm}$. These values are listed in Fig. 2.

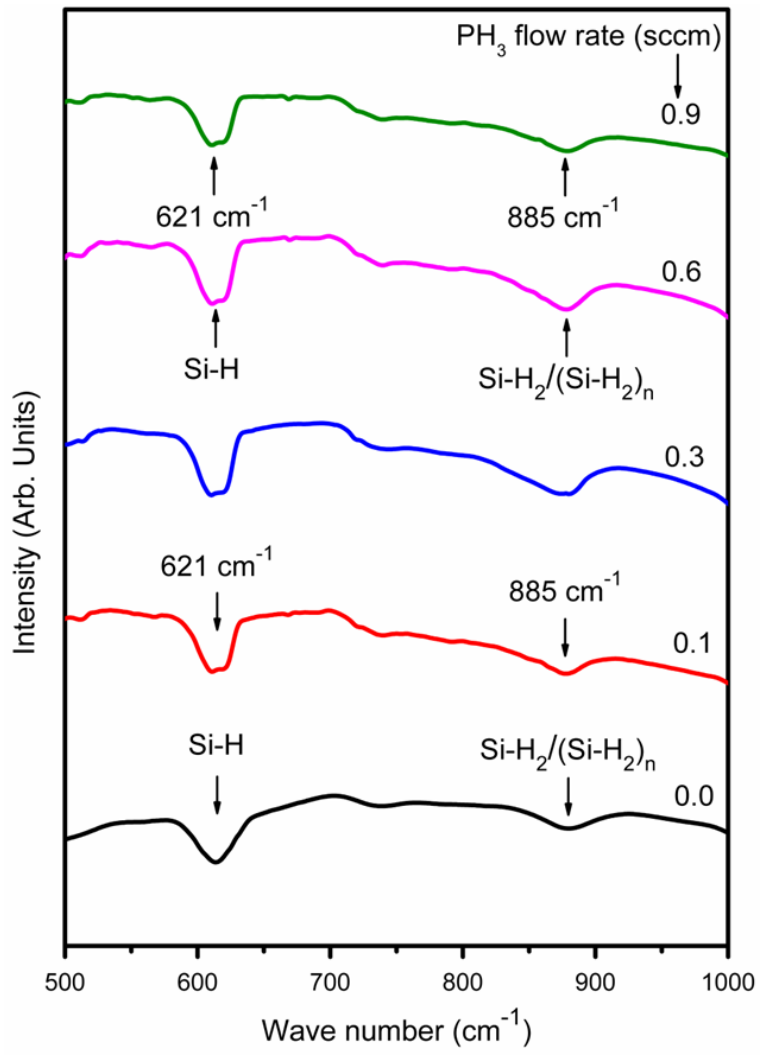

Fig. 5 FTIR spectra of phosphorous doped nc-Si:H films deposited by Cat-CVD technique at various $\mathrm{PH} 3$ flow rates.

\section{3: Raman spectroscopy analysis}

In Fig. 3, room temperature Raman spectra are shown for phosphorus doped nc-Si:H films deposited at different $\mathrm{PH}_{3}$ flow rates. As shown in figure, the films prepared at $\mathrm{PH}_{3}$ flow rate of $0.0 \mathrm{sccm}$ (undoped) has a sharp peak at $\sim 517.8 \mathrm{~cm}^{-1}$, corresponding to the transverse optic (TO) phonon vibration, which is due to the presence of nano-crystalline phase. ${ }^{[34]}$ With an increase in the $\mathrm{PH}_{3}$ flow rate, the intensity of TO peak is decreased. This is due to an reduction in the crystalline volume fraction as the $\mathrm{PH}_{3}$ flow rate is increased. From these results, it is observed that the addition of phosphorous in nc-Si:H network causes nano-crystalline to amorphous transition in the films. These results further confirm the phosphorous induced amorphization in the nc-Si:H network. To determine the crystalline volume fraction ( $\mathrm{X}_{\text {Raman }}$ ) and size of the crystallites $\left(\mathrm{d}_{\text {Raman }}\right)$, each Raman spectrum is de-convoluted in the range $350-550 \mathrm{~cm}^{-1}$ into three peaks at 515-520, 470-484 and 500$510 \mathrm{~cm}^{-1}$ corresponding to crystalline phase, intermediate phase and amorphous phase, respectively. ${ }^{[33]}$

A de-convoluted Raman spectrum for the $\mathrm{PH}_{3}$ flow rate of $0.0 \mathrm{sccm}$ (undoped) is shown in Fig. 4. The volume fraction of crystallites $\left(\mathrm{X}_{\text {Raman }}\right)$ is estimated using Equation (2):[36]

$$
X_{\text {Raman }}=\frac{I_{c}+I_{m}}{I_{c}+I_{m}+\sigma I_{s}}
$$

where $\sigma$ is $1.0,{ }^{[3]]} I_{c}$ is the intensity of the peak in the range $515-520 \mathrm{~cm}^{-1}$ corresponding to the crystalline phase, $I_{m}$ is the intensity of the peak in the range of $500-510 \mathrm{~cm}^{-1}$ corresponding to the intermediate phase and $I_{a}$ is the intensity of the peak in the range of $470-484 \mathrm{~cm}^{-1}$ corresponding to the amorphous phase of the phosphorus doped nc-Si:H thin films.

The crystallite size $\left(d_{\text {Raman }}\right)$ is calculated using Equation (3):[38]

$$
d_{\text {Raman }}=2 \pi \sqrt{\frac{\beta}{\Delta \omega}} .
$$

where $\Delta \omega$ is the shift in the peak from the peak centered at $520 \mathrm{~cm}^{-1}$ corresponding to the c-Si and $\beta=2.0 \mathrm{~cm}^{-1} \mathrm{~nm}^{2}$. ${ }^{[39]}$

For the undoped nc-Si:H film, the crystalline volume fraction is $\sim 55 \%$ and as the $\mathrm{PH}_{3}$ flow rate is increased to 0.9 $\mathrm{sccm}$, and the crystalline volume fraction shrinks to $41 \%$. These results exactly match with the low angle XRD analysis, which also confirms the doping induced amorphization in the nc-Si:H films. But it is observed that the crystallite size remains invariant of the $\mathrm{PH}_{3}$ flow rate. It is $\sim 6 \mathrm{~nm}$ for all $\mathrm{PH}_{3}$ flow rates.

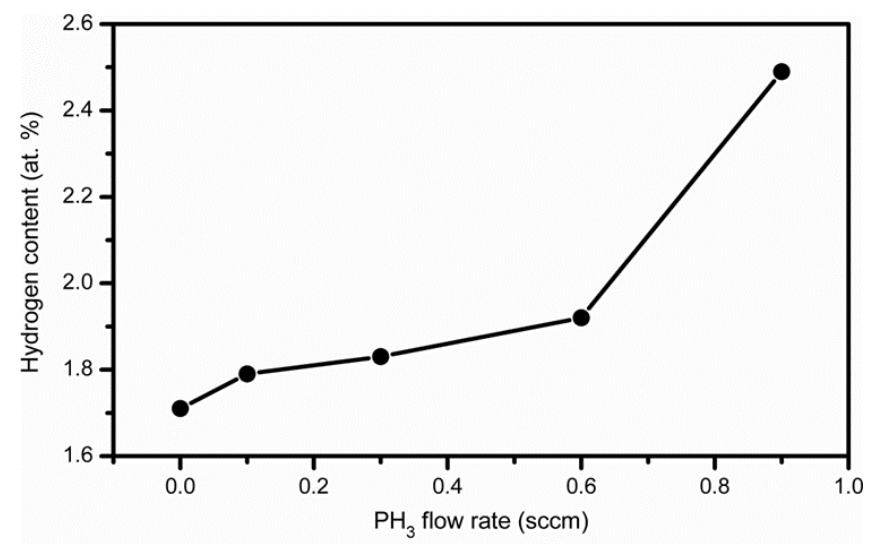

Fig. 6 Variation of hydrogen content as a function of $\mathrm{PH}_{3}$ flow rate for the phosphorous doped nc-Si:H films deposited by CatCVD technique. 

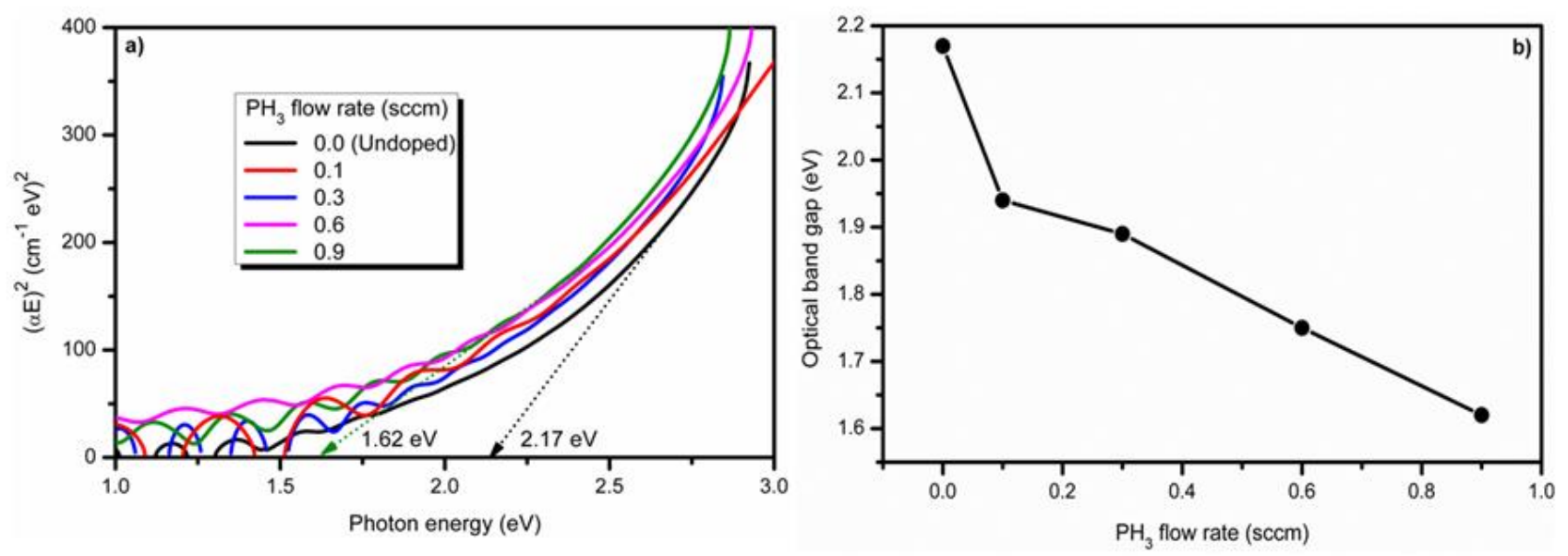

Fig. 7 a) The Tauc plot used to estimate the optical band gap of phosphorous doped nc-Si:H films, and b) variation of band gap as a function of $\mathrm{PH}_{3}$ flow rate.

\subsection{FTIR spectroscopic analysis}

Fig. 5 shows the FTIR spectra of phosphorus doped nc-Si:H films prepared at various $\mathrm{PH}_{3}$ flow rates. For all the films, the FTIR spectra show two major absorption bands, which are the mono-hydride (Si-H) wagging mode at $\sim 621 \mathrm{~cm}^{-1}{ }^{[40,41]}$ and the di-hydride or poly-hydride complexes such as $\left(\mathrm{Si}-\mathrm{H}_{2}\right)_{\mathrm{n}}$ stretching/bending mode at $\sim 885 \mathrm{~cm}^{-1}$. ${ }^{[42]}$ It is observed that the depth of the bands located at $\sim 621$ and $885 \mathrm{~cm}^{-1}$ increases with an increase in the $\mathrm{PH}_{3}$ flow rate. The hydrogen may be attached with silicon in the form of mono-hydride (Si-H), dihydride $\left(\mathrm{Si}-\mathrm{H}_{2}\right)$, tri-hydride $\left(\mathrm{Si}-\mathrm{H}_{3}\right)$ or poly-hydride $\left(\mathrm{Si}-\mathrm{H}_{2}\right)_{\mathrm{n}}$ configurations.

All these bonding configurations of silicon and hydrogen contribute to the vibrational mode at $\sim 621 \mathrm{~cm}^{-1}$. ${ }^{[43,44]}$ Thus, to calculate the total amount of bonded hydrogen content in the film, the area coming under the absorption peak at $\sim 621 \mathrm{~cm}^{-1}$ was integrated. The total bonded hydrogen content is estimated by using the procedures given by Langford et al.. ${ }^{[45]}$ The variation of hydrogen content in the phosphorus doped nc$\mathrm{Si}: \mathrm{H}$ films with an increase in the $\mathrm{PH}_{3}$ flow rate is shown in Fig. 6. It is observed that the total atomic $\mathrm{H}$ content in the film is increased slowly from 1.7 to 2.5 at. \% with an increases in the $\mathrm{PH}_{3}$ flow rate from 0.0 to $0.9 \mathrm{sccm}$. The increase in the hydrogen content with an increase in the $\mathrm{PH}_{3}$ flow rate is the result of amorphization of nc-Si:H films due to incorporation of phosphorus atoms in the host nc-Si:H matrix. As seen from the XRD and Raman spectroscopy analysis, when phosphorus atoms are incorporated in the nc-Si:H films, the amorphization of the film takes place. The incorporation of more phosphorus atoms with an increase in $\mathrm{PH}_{3}$ flow rate increases the defect states such as dangling bonds and micro-voids etc. in the films. These dangling bonds are then compensated by the hydrogen atoms. This is the reason for the increase in hydrogen content in the films with an increase in the $\mathrm{PH}_{3}$ flow rate.

\subsection{UV-Visible spectroscopy analysis}

The optical band gap of nc-Si:H films at various $\mathrm{PH}_{3}$ flow rate was calculated from the UV-Visible spectroscopy. The absorption coefficient $(\alpha)$ was estimated from transmission $(T)$ and reflection $(R)$ in the UV-Visible spectra. The $\alpha$ was calculated for each wavelength using Equation (4):

$$
\alpha=-\frac{1}{d} \ln \left(\frac{T}{1-R}\right)
$$

where $d$ is the thickness of film. The values of band gap were determined by plotting $(\alpha h v)^{2}$ versus photon energy $(E=h v)$ (Tauc plot) and by extrapolating the curve to the ho axis using equation, ${ }^{[46]}$

$$
(\alpha h v)^{1 / 2}=\mathrm{B}\left(\mathrm{h} v-\mathrm{E}_{\mathrm{g}}\right)
$$

where $\mathrm{B}$ is energy independent constant, $\mathrm{h}$ is the Plank constant and $v$ is frequency of incident photon radiation. Fig. 7 (a) shows the Tauc plots used to determine the optical band gap of the phosphorus doped nc-Si:H films. The variation of band gap as a function of $\mathrm{PH}_{3}$ flow rate is depicted in Fig. 7 (b). It is observed that the band gap is gradually decreased from 2.17 to $1.62 \mathrm{eV}$ when the $\mathrm{PH}_{3}$ flow rate is increased from 0.0 to $0.9 \mathrm{sccm}$. In the PE-CVD deposited films, the band gap is increased as the hydrogen content is increased. ${ }^{[47,48]}$ In this study, the optical band gap is observed to drop from 2.17 to $1.62 \mathrm{eV}$ with an increase in the $\mathrm{PH}_{3}$ flow rate while the total hydrogen content shows an increasing trend (see Fig. 6). For the Cat-CVD grown nc-Si:H films, these two results are contradictory. Thus, for the nc-Si:H films grown by Cat-CVD, the only hydrogen content cannot account for the change in the optical band gap.

The decrease in the crystalline volume fraction in the nc$\mathrm{Si}: \mathrm{H}$ films with a rise in the $\mathrm{PH}_{3}$ flow rate may be attributed to the decrease in optical band gap. In the present study, the optical band gap remains high $(\sim 1.62 \mathrm{eV})$ irrespective of maximum hydrogen content ( 2.5 at.\%). In the nc-Si:H films, the crystallites of nc-Si:H are embedded in amorphous matrix of Si:H. This implies that nc-Si:H has both amorphous as well as crystalline phases. Therefore, the optical band gap of the nc-Si:H should lie in between the band gaps of amorphous and crystalline phases of Si:H. ${ }^{[49]}$ Even though the hydrogen content is comparatively low for all nc-Si:H films, the band 
gap has a considerable high value. The reason for this is the presence of micro-voids due to the incorporation of phosphorus atoms in the nc-Si:H films. Due to the presence of micro-voids, the density of the nc-Si:H gets reduced, which causes an increase in the $\mathrm{Si}-\mathrm{Si}$ bond length. The increased $\mathrm{Si}$ $\mathrm{Si}$ bond length reduces the absorption and there is a blue shift in the transmission curve, which results in a higher band gap.

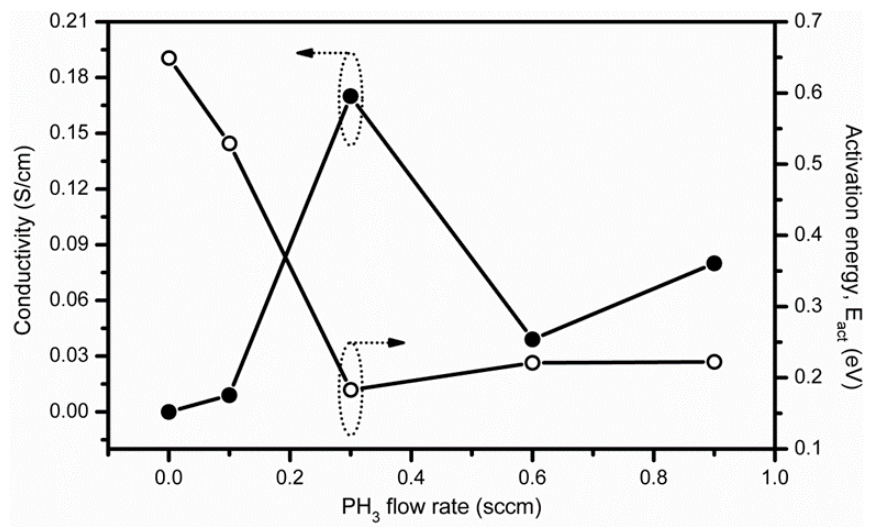

Fig. 8 Variation of dark conductivity $\left(\sigma_{d a r k}\right)$ and charge carrier activation energy $\left(E_{a c t}\right)$ as a function of the $\mathrm{PH}_{3}$ flow rate for the phosphorous doped nc-Si:H films deposited by Cat-CVD technique.

\subsection{Electrical properties}

The variation in activation energy $\left(E_{a c t}\right)$ and dark conductivity $\left(\sigma_{\text {dark }}\right)$ with an increase in the $\mathrm{PH}_{3}$ flow rate for the phosphorus doped nc-Si:H films is shown in Fig. 8. The room temperature $\sigma_{\text {Dark }}$ was measured in the coplanar geometry by evaporating the $\mathrm{Al}$ contacts on the films using vacuum thermal evaporation using Equation (6):

$$
\sigma_{\text {Dark }}=\left[\frac{V \times \mathrm{d} \times \omega}{I \times \ell}\right]^{-1}
$$

where $V$ is the applied voltage (volts), $I$ is current (amperes), $\mathrm{d}$ is thickness $(\mathrm{cm}), \omega$ is width $(\mathrm{cm})$ and $l$ is the distance between the electrodes $(\mathrm{cm})$.

The temperature dependent conductivity was measured in the range $320-425 \mathrm{~K}$ and activation energy was calculated using Equation (7):

$$
\sigma_{\text {Dark }}=\sigma_{0} \exp \left[-\frac{E_{a c t}}{k_{B} \times T}\right]
$$

where $\sigma_{0}$ is the conductivity pre-exponential factor, $E_{a c t}$ is the activation energy and $k_{B}$ is the Boltzmann constant and $T$ is temperature in Kelvin. As shown in Fig. 8, for pure nc-Si:H film, the dark conductivity is $3.7 \times 10^{-8} \mathrm{~S} / \mathrm{cm}$. When the $\mathrm{PH}_{3}$ flow rate is maintained at $0.1 \mathrm{sccm}$, the dark conductivity is increased to $0.092 \mathrm{~S} / \mathrm{cm}$. With a further increase in the $\mathrm{PH}_{3}$ flow rate, i.e. from 0.1 to $0.3 \mathrm{sccm}$, the dark conductivity reaches a maximum value of $1.52 \mathrm{~S} / \mathrm{cm}$. The conductivity is decreased with a further increase in the $\mathrm{PH}_{3}$ flow rate. As expected, the activation energy shows exactly a reverse trend. The activation energy values are found less than $0.7 \mathrm{eV}$, suggesting that all films are n-type. Initially, with an increase in the $\mathrm{PH}_{3}$ flow rate, the incorporation of phosphorus atoms in the nc-Si:H films is increased. Therefore, the number of charge carriers in the film is increased, which results in an increment in the dark conductivity. Further, the dark conductivity is decreased suddenly beyond an optimum value of $\mathrm{PH}_{3}$ flow rate $(0.3 \mathrm{sccm})$. This indicates the formation of amorphous phase beyond $0.3 \mathrm{sccm}$ of $\mathrm{PH}_{3}$ flow rate. The Raman and XRD spectra also show the same results.

\section{Conclusion}

In this paper, we report the effect of phosphine gas conditions on the structural and opto-electronic properties of nc-Si:H films prepared by the catalytic chemical vapor deposition technique (Cat-CVD). Intrinsic (undoped) and phosphorous doped nc-Si:H films were prepared using silane $\left(\mathrm{SiH}_{4}\right)$ and phosphine $\left(\mathrm{PH}_{3}, 1 \%\right.$ in hydrogen) gases. The study of nc-Si:H film properties with a variation in the $\mathrm{PH}_{3}$ flow rate was carried out using different analysis techniques such as UV-VIS spectroscopy, FTIR spectroscopy, low angle XRD, Raman and electrical conductivity measurements etc. From Raman and XRD analysis, it was observed that the incorporation of phosphorus in nc-Si:H causes a transition from nanocrystalline to amorphous phase. The FTIR spectroscopy analysis showed that the bonded hydrogen in undoped and doped nc-Si:H films mainly occurred in the mono-hydride (Si$\mathrm{H})$ and di-hydride $\left(\mathrm{Si}-\mathrm{H}_{2}\right)$ or poly-hydride $\left(\mathrm{Si}-\mathrm{H}_{2}\right)_{\mathrm{n}}$ configurations. The optical band gap of phosphorus doped ncSi:H films was decreased from 2.17 to $1.62 \mathrm{eV}$ when the $\mathrm{PH}_{3}$ flow rate was increased from 0.0 to $0.9 \mathrm{sccm}$. The maximum dark conductivity has been observed for the phosphorus doped nc-Si:H films synthesized at $0.3 \mathrm{sccm} \mathrm{PH}_{3}$ flow rate. At an optimized $\mathrm{PH}_{3}$ flow rate $(0.3 \mathrm{sccm})$, n-type nc-Si:H film was synthesized with a reasonably high deposition rate $(\sim 29.6$ $\AA / \mathrm{s})$, high band gap $(\sim 1.89 \mathrm{eV})$, high dark conductivity ( $1.52 \mathrm{~S} / \mathrm{cm})$ and low charge carrier activation energy $(0.19 \mathrm{eV})$ with a minimum hydrogen content $(\sim 1.83$ at.\%). The synthesized films can have applications useful in the tandem solar cells as n-layer.

\section{Acknowledgements}

Ajinkya Bhorde is thankful to Department of Science and Technology (DST), Government of India for INSPIRE Ph. D. fellowship. Rahul Aher is thankful to Savitribai Phule Pune University, Pune for the award of Bharatratna J. R. D. Tata Gunwant Sanshodhak Shishyavruti. Subhash Pandharkar, Shruthi Nair, Pratibha Shinde, Ashish Waghmare, Yogesh Hase, Priti Vairale, Ashvini Punde and Vidya Doiphode are thankful to the Ministry of New and Renewable Energy (MNRE), Government of India for the financial support under National Renewable Energy Fellowship (NREF) program. Haribhau Borate is grateful to University Grant Commission (UGC), New Delhi for Teacher Fellowship Faculty Improvement Program (FIP) for college teachers. Sandesh Jadkar and Mohit Prasad is thankful to University Grants Commission (UPE program), New Delhi and Indo-French Centre for the Promotion of Advanced Research-CEFIPRA, 
Department of Science and Technology, New Delhi for special financial support.

\section{Supporting information}

Not applicable.

\section{Conflict of interest}

There are no conflicts to declare.

\section{References}

[1] R. Street, Technology and Application of Amorphous Silicon, Springer Verlag, New York, 2000.

[2] S. Filonovich, H. Águas, T. Busani, A. Vicente, A. Araújo, D. Gaspar, M. Vilarigues, J. Leitao, E. Fortunato, R. Martins, Sci. Technol. Adv. Mater, 2012, 13, 045004, doi: 10.1088/14686996/13/4/045004.

[3] P. Sharma, N. Gupta, In Nanomaterials and Their Applications, Z. Khan, (Ed.), Springer, Singapore, pp. 209-233, 2018.

[4] Z. Lin, Y. Zhang, W. Zhang, J. Song, H. Li, C. Song, Y. Guo, R. Huang, IEEE Photo J. 2018, 10, 8400108, doi: 10.1109/JPHOT.2018.2818194.

[5] F. Sahli, J. Werner, B. Kamino, M. Bräuninger, R. Monnard, B. Salomon, L. Barraud, L. Ding, J. Leon, D. Sacchetto, G. Cattaneo, M. Despeisse, M. Boccard, S. Nicolay, Q. Jeangros, B. Niesen, C. Ballif, Nat. Mater, 2018, 17, 820-826, doi: 10.1038/s41563-018-0115-4.

[6] M. Martuza, S. Ghanbarzadeh, C. Lee, C. Con, K. Karim, IEEE Trans. Electr. Dev., 2018, 65, 584-590, doi: 10.1109/TED.2017.2782769.

[7] P. Rodriguez, W. Vijselaar, J. Huskens, M. Stam, M. Falkenberg, M. Zeman, W. Smith, A. Smets, Prog. Photovoltaics, 2019, 27, 245-254, doi: 10.1002/pip.3085.

[8] C. Lee, A. Sazonov, A. Nathan, Appl. Phys. Lett., 2005, 86, 222106, doi: 10.1063/1.1942641.

[9] M. Jana, D. Das, A. Barua, J. Appl. Phys., 2002, 91, 5442, doi: 10.1063/1.1454201.

[10] H. Zhou, D. Wei, S. Xu, S. Xiao, L. Xu, S. Huang, Y. Guo, W. Yan, M. Xu, J. Appl. Phys., 2011, 110, 023517, doi: 10.1063/1.3605288

[11] S. Ishihara, D. He, M. Nakata, I. Shimizu, Jpn. J. Appl. Phys., 1993, 32, 1539, doi: 10.1143/JJAP.32.1539.

[12] A. Shah, J. Meier, E. Vallat-Sauvain, N. Wyrsch, U. Kroll, U. Droz, U. Graf, Sol. Energy Mater. Sol. Cells, 2003, 78, 469-491, doi: 10.1016/S0927-0248(02)00448-8.

[13] K. Yamamoto, A. Nakajima, M. Yoshimi, T. Sawada, S Fukuda, T. Suezaki, M. Ichikawa, Y. Koi, M. Goto, H. Takata, T. Sasaki, Y. Tawada, Proc. $3^{\text {rd }}$ WCPEC, Osaka, Japan, pp. 2789, 2003

[14] S. Zhang, X. Zeng, J. Semicond., 2017, 38, 114007, doi: 10.1088/1674-4926/38/11/114007.

[15] J. Ma, H. Bai, J. Zhang, Y. Yuan, J. Ni, K. Zhang, Sol. Energy Mater. Sol. Cells, 2016, 157, 923-929, doi: 10.1016/j.solmat.2016.08.001 [16] J. Shim, J. Kim, N. Cho, Trans. Electr. Electron. Mater., 2019, 2010, 257, 817-822, doi: 10.1016/j.apsusc.2010.07.071. 20, 85-91, doi: 10.1007/s42341-019-00104-y.

[17] S. Whibi, L. Derbali, P. Tristant, C. Jaoul, M. Colas, R. Mayet, J. Cornette, H. Ezzaouia, J. Mater. Sci.: Mater. Electron., 2019, 30, 2351-2359, doi: 10.1007/s10854-018-0508-9.

[18] P. Sharma, N. Tripathi, N. Gupta, J. Mater. Sci., 2017, 28, 3891-3896, doi: 10.1007/s10854-016-6002-3.

[19] Bu, A. Flewitt, W. Miline, Plasma Sci. Techn., 2010, 12, 608613, doi: 10.1088/1009-0630/12/5/19.

[20] F. Sahraoui, A. Kebab, A. Bouhekka, J. Sib, Y. Bouizem, D. Benlakehal, L. Chahed, Optik, 2018, 168, 65-76, doi: 10.1016/j.ijleo.2018.03.097.

[21] A. Kherodia, V. Kheraj, A. Panchal, Silicon, 2018, 10, 1475 1485, doi: 10.1007/s12633-017-9629-7.

[22] R. Karmouch, Int. J. Eng. Res., 2016, 7/12, 1498-1526.

[23] R. Tripathi, O. Panwar, I. Rawal, B. Singh, B. Yadav, J. Taiwan Inst. Chem. E., 2018, 86, 185-191, 10.1016/j.jtice.2018.01.051.

[24] A. Pevtsov, N. Feoktistov, Tech. Phys. Lett., 2002, 28, 305307, doi: 10.1134/1.1476999.

[25] Y. He, C. Yin, G. Cheng, L. Wang, X. Liu, G. Hu, J. Appl. Phys., 1994, 75, 797, doi: 10.1063/1.356432.

[26] S. Major, S. Kumar, M. Bhatnagar, K. Chopra, Appl. Phys. Lett., 1986, 49, 394, doi: 10.1063/1.97598.

[27] R. Schropp, J. Rath and H. Li, J. Cryst. Growth, 2009, 311, 760-764, https://doi.org/10.1016/j.jcrysgro.2008.09.155.

[28] P. Gogoi, H. Jha, P. Agarwal, Thin Solid Films, 2010, 518 , 6818-6828, doi: 10.1016/J.TSF.2010.06.040.

[29] R. Swanepoel, J. Phys. E Sci. Instrum., 1983, 16, 1214, doi: 10.1088/0022-3735/16/12/023.

[30] S. Filonovich, M. Ribeiro, A. G. Rolo and P. Alpuim, Thin Solid Films, 2008, 516, 576-579, doi: 10.1016/j.tsf.2007.06.176. [31] R. Martins, A. Maqarico, I. Ferreira, R. Nunes, A. Bicho, E. Fortunato, Thin Solid Films, 1997, 303, 47-52, doi: 10.1016/S0040-6090(97)00087-4.

[32] B. Aken, C. Devilee, M. Dorenkamper, M. Geusebroek, M. Heijna, J. Loffler, W. Soppe, J. Non-Cryst. Solids, 2008, 354, 1925, doi: 10.1016/j.jnoncrysol.2007.09.024.

[33] B. Cullity, S. Stock, Elements of X-ray Diffraction, 3rd Edition, Princeton Hall, 2001.

[34] Z. Li, W. Li, Y. Jiang, H. Cai, Y. Gong, J. He, J. Raman Spectrosc., 2011, 42, 415-421, doi: 10.1002/jrs.2711.

[35] D. Marquardt, J. Soc. Ind. Appl. Math., 1963, 11, 431-441, doi: 10.1137/0111030.

[36] D. Raha, D. Das, J. Phys. D: Appl. Phys., 2008, 41, 85303, doi: 10.1088/0022-3727/41/8/085303.

[37] M. Acciarri, S. Binetti, M. Bollani, A. Comotti, L. Fumagalli, S. Pizzini, H. Kanel, Sol. Energ. Mat. Sol., Cells, 2005, 87, 1124., doi: 10.1016/j.solmat.2004.09.012.

[38] Parramon, D. Gracin, M. Modereanu, A. Gajovic, Sol. Energ. Mat. Sol. Cells, 2009, 93, 1768-1772, doi: 10.1016/j.solmat.2009.06.008.

[39] Y. He, C. Yin, G. Cheng, L. Wang, X. Lie, G.Y. Hu, J. Appl. Phys., 1994, 75, 797, doi: 10.1063/1.356432.

[40] Y. Qin, H. Yan, F. Li, L. Qiao, Q. Liu, D. He, Appl. Surf. Sci., 
[41] A. Remolina, B. Monroy, M. Sanchez, A. Ponce, M. Bizarro, [47] G. Cody, C. Wronski, B. Abeles, R. Stephens, B. Brooks, J. Alonso, A. Ortiz, G. Santana, Nanotechnol., 2009, 20, 245604, Solar cells, 1980, 2, 227-240, doi: 10.1016/0165-1633(82)90065doi: 10.1088/0957-4484/20/24/245604.

$\mathrm{X}$.

[42] Knights, G. Lucovsky, R. Nemanich, J. Non-Cryst. Solids, 1979, 32, 393-403, doi: 10.1016/0022-3093(79)90084-X.

[43] W. Lau, Infrared Characterization of Microelectronics, World Scientific Publication, Singapore, 1999. [44] H. Shanks, C. Fang, L. Ley, M. Cardona, F. Demond, S. Condens. Matter, 2008, 20, 335215, doi: 10.1088/0953Kalbitzer, Phys. Status Solidi B, 1980, 100, 43-56, doi: 8984/20/33/335215.

10.1002/pssb.2221000103.

[45] A. Langford, M. Fleet, B. Nelson, W. Lanford, N. Maley, Phys. Rev. B, 1992, 45, 13367, doi: 10.1103/PhysRevB.45.13367.

[46] J. Tauc, A. Menth, J. Non. Cryst. Solids., 1972, 8-10, 569585, https://doi.org/10.1016/0022-3093(72)90194-9.
[48] J. Wallinga, W. Arnoldbik, A. Vredenberg, R. Schropp, W. Weg, J. Phys. Chem. B, 1998, 102, 6219-6224, doi: 10.1021/jp9814471.

[49] S. Kumar, P. Dixit, C. Rauthan, A. Parashar, J. Gope, J. Phys.

Publisher's Note Engineered Science Publisher remains neutral with regard to jurisdictional claims in published maps and institutional affiliations. 